\title{
Utilização de enzimas proteolíticas para produção de hidrolisados proteicos a partir de carcaças de frango desossadas manualmente
}

\author{
Use of proteolytic enzymes for the production of protein hydrolysates from \\ manually deboned chicken carcasses
}

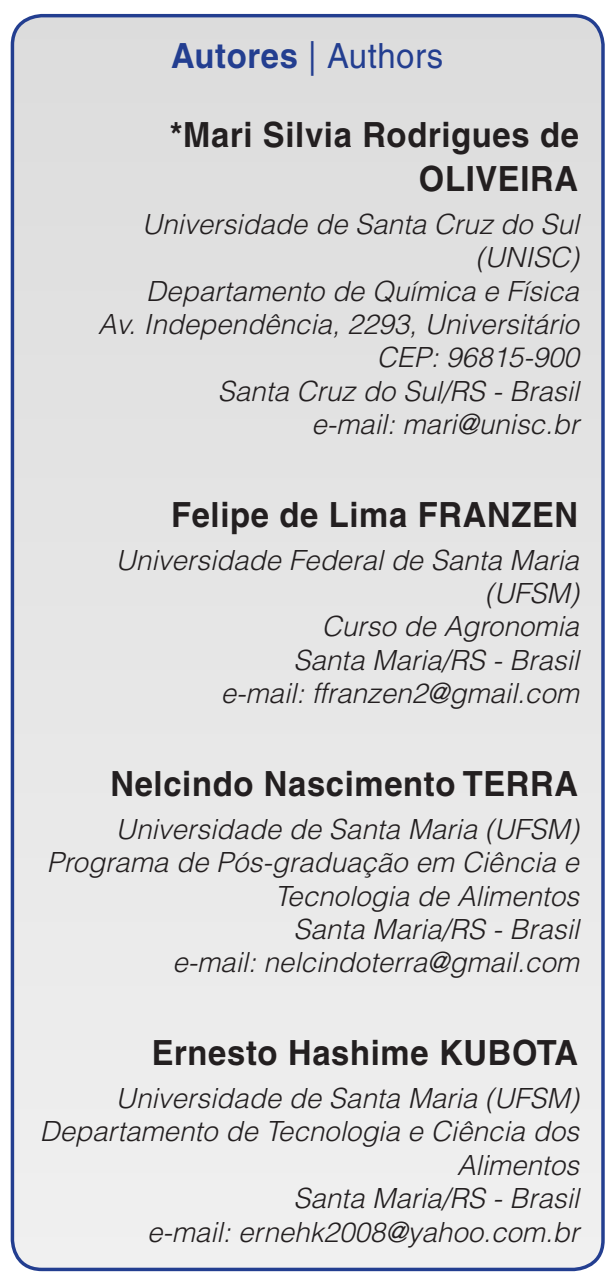

*Autor Correspondente / Corresponding Author

Recebido: Ago. 07, 2014

Aprovado: Nov. 16, 2015

\section{Resumo}

O emprego de hidrolisados proteicos, oriundos de fontes animais e vegetais, em formulações específicas, é uma área de crescente interesse. O objetivo deste trabalho foi desenvolver diferentes hidrolisados liofilizados com alto valor proteico, obtidos a partir da hidrólise enzimática de carcaças de frango manualmente desossadas (CMD), um subproduto da indústria avícola, que normalmente é utilizado para a fabricação de carne mecanicamente separada (CMS). A matéria-prima utilizada foram carcaças de frango desossadas manualmente e congeladas (CMD), provenientes de animais abatidos com aproximadamente 42 dias de vida e com peso médio de $2,5 \mathrm{~kg}$, adquiridas em um abatedouro da região sul do Brasil. Antes de serem processadas, foram descongeladas sob temperatura de refrigeração e cortadas em pedaços menores com faca de aço inox para facilitar sua homogeneização durante o tempo de hidrólise. Foram utilizadas três enzimas comerciais, Papaína ${ }^{\circledR}$, Flavourzyme ${ }^{\circledR}$ e Protamex ${ }^{\circledR}$. A hidrólise ocorreu em banho termostatizado com temperatura, tempo e pH controlados. Foi ealizada a composição proximal da matéria-prima e dos hidrolisados liofilizados, atividade de água dos hidrolisados liofilizados e foram feitas as seguintes análises de controle da hidrólise: grau de hidrólise, teores de proteínas, sólidos totais, cinzas, caracterização de aminoácidos dos hidrolisados, rendimento, percentual de hidrólise e cor dos hidrolisados. Os resultados foram submetidos à análise de variância e teste de Tukey para comparação de médias. O grau de hidrólise maior foi com a Protamex, seguido da Papaína e da Flavourzyme. O teor de proteínas após os 120 minutos de hidrólise não variou estatisticamente $(p>0,05)$ entre a Papaína e a Flavourzyme. A composição de aminoácido demonstra que o hidrolisado obtido da Papaína possui uma composição mais próxima da recomendada pelos órgãos de controle. Concluiu-se que os hidrolisados proteicos obtidos da carcaça manualmente desossada (CMD) de frango apresentaram alto conteúdo proteico, caracterizando-se como matéria-prima promissora na formulação de dietas especiais.

Palavras-chave: Carcaça de frango manualmente desossada (CMD); Hidrolisado proteico; Hidrólise enzimática.

\section{Summary}

The use of protein hydrolysates, derived from animal and vegetable sources, in specific formulations, is an area of growing interest. The goal of this study was to develop different freeze-dried powder hydrolysates with high protein value, obtained from the enzymatic hydrolysis of manually deboned chicken carcasses (MDC), a by-product of the poultry industry which is normally used in the production of mechanically deboned meat (MDM). The raw material used was frozen manually deboned chicken carcasses (MDC), obtained from animals slaughtered at approximately 42 days of age with an average weight of $2.5 \mathrm{~kg}$, acquired from an abattoir in southern Brazil. Before use, they were thawed under refrigeration, and cut into smaller pieces with a stainless steel knife for easier mixing during the hydrolysis time. Three commercial enzymes, Papain ${ }^{\circledR}$, Flavourzyme ${ }^{\circledR}$ and Protamex ${ }^{\circledR}$ were used. Hydrolysis occurred in a thermostatic bath with controlled 
temperature, time and $\mathrm{pH}$. The proximal compositions of the raw material and freeze-dried hydrolysates and the water activity of the freeze-dried hydrolysates were determined, and the following analyses carried out to control the hydrolysis: degree of hydrolysis, protein, total solids and ash contents, characterization of the amino acids in the hydrolysates, yield, percent hydrolysis and colour of the hydrolysates. The results were evaluated by the analysis of variance and Tukey's means comparison test. The degree of hydrolysis was highest with Papain, followed by Protamex and Flavourzyme and after 120 minutes of hydrolysis the protein content did not vary significantly $(p>0.05)$ between Papain and Flavourzyme. The amino acid composition showed that the hydrolysate obtained with papain had a composition closer to that recommended by the control authorities. It was concluded that the protein hydrolysates obtained from manually deboned chicken carcasses (MDC) had a high protein content, characterizing them as a promising raw material for the formulation of special diets.

Key words: Manually deboned chicken carcass (MDC); Protein hydrolysate; Enzymatic hydrolysis.

\section{Introdução}

O crescimento da demanda global de carne de frango devido ao aumento da renda per capita da população mundial e da mudança de hábitos e preferências alimentares dos consumidores impulsiona as melhorias do processo produtivo visando, além do aumento da produtividade, produtos de melhor qualidade (BRASIL, 2011).

Desta forma, a comercialização e o consumo de cortes de carne de frango no Brasil têm aumentado visivelmente, devido a sua atratividade e praticidade. Neste contexto, as indústrias nacionais processadoras de carne de frango procuraram se estruturar e se adequar ao mercado externo. Além disso, a Divisão de Inspeção de Produtos de Origem Animal (DIPOA) do Ministério da Agricultura, Pecuária e Abastecimento (MAPA) criou normas para padronizar as atividades de corte nos abatedouros-frigoríficos (OLIVO, 2006).

A presença do Brasil no cenário mundial da exportação da carne de frango justifica-se pela expansão das plantas industriais avícolas, pela produção de cortes especiais, porções ou peças diferenciadas ao invés do frango inteiro, produtos com alto valor agregado, produtos congelados, carnes pré-cozidas, empanados e hambúrgueres de frango associados ao baixo custo de produção, ocasionado principalmente pela disponibilidade de matérias-primas indispensáveis à produção, como o milho e a soja, possibilitam a entrada do produto brasileiro em novos mercados consumidores (BELUSSO; HESPANHOL, 2010).

A estrutura óssea final da desossa manual pode servir de fonte proteica para a obtenção de hidrolisados proteicos, utilizados em formulações específicas tais como produtos alimentares geriátricos, suplementos energéticos, dietas para controle de peso ou terapêuticas ou ainda dietas entéricas (SLIZYTE et al., 2005). A grande maioria dos hidrolisados utilizados, atualmente, são obtidos da caseína e da proteína de soja.

As metodologias mais usuais para a obtenção dos hidrolisados proteicos são a hidrólise alcalina, a hidrólise enzimática e a hidrólise ácida ou a combinação de dois ou mais destes métodos (ADLER-NISSEN, 1986; LAHL; BRAUN, 1994).

No método enzimático, o princípio básico para a obtenção do hidrolisado proteico envolve a quebra hidrolítica das longas cadeias de moléculas proteicas pela adição de enzimas vegetais ou por proteases microbianas. A catálise enzimática possui benefícios, como o aumento da qualidade dos produtos, a redução dos custos de laboratório e de maquinário, visando, com isto, à melhoria ou à obtenção de produtos diferenciados na indústria alimentícia (MUSSATTO et al., 2007).

Os hidrolisados proteicos são utilizados principalmente na gestão nutricional de indivíduos que não conseguem digerir totalmente a proteína pura. Principalmente os hidrolisados ricos em peptídeos de baixo peso molecular, especialmente di- e tripeptídeos, com o mínimo possível de aminoácidos livres, demonstram possuir mais utilizações alimentares, devido aos seus valores nutricionais e terapêuticos aumentados (BHASKAR et al., 2007).

O objetivo deste trabalho foi avaliar hidrolisados liofilizados, obtidos a partir da hidrólise de carcaças de frango manualmente desossadas (CMD), utilizando diferentes enzimas proteolíticas, e também o processo de obtenção destes pela composição proximal, grau de hidrólise e rendimento. 
Utilização de enzimas proteolíticas para produção de hidrolisados proteicos a partir de carcaças de frango desossadas manualmente

OLIVEIRA, M. S. R. et al.

\section{Material e métodos}

\subsection{Material}

A matéria-prima utilizada foi a estrutura óssea oriunda da desossa manual, adquirida de um abatedouro da região sul do Brasil, aqui denominada de carcaça de frango manualmente desossada (CMD) e congelada, obtida de animais abatidos com aproximadamente 42 dias de vida e com peso médio de $2,5 \mathrm{~kg}$. Antes da sua utilização, foi descongelada sob temperatura de refrigeração e cortada em pedaços menores com faca de aço inox para facilitar sua homogeneização durante o tempo de hidrólise. As amostras de carne utilizadas para a realização da composição proximal foram obtidas pela remoção da carne aderida na estrutura com uma faca de aço inox comum e posteriormente homogeneizadas em liquidificador. As amostras experimentais apresentaram um $\mathrm{pH}$ médio de 6,34.

\subsection{Enzimas}

As enzimas utilizadas neste experimento são as mesmas descritas em Oliveira et al. (2014). A papaína comercialmente pura denominada Papain, From Papaya Látex-1,5 units/MG solid (Sigma Aldrich ${ }^{\circledR}$ ) é uma cisteína protease da família C1-peptidase. Foi utilizada também a Flavourzyme, que é uma aminopeptidase produzida por fermentação submersa de uma linhagem selecionada do fungo Aspergillus oryzae e utilizada para hidrólise de proteínas sob condições neutras ou levemente ácidas. A Flavourzyme1000 L ${ }^{\circledR}$ é uma exopeptidase com uma atividade de $1 \mathrm{LAPU} / g$. Uma LAPU (Unidade Leucina Aminopeptidase) é a quantidade de enzima que hidrolisa $1 \mu \mathrm{mol}$ de leucina- $\rho$-nitroanilida por minuto. A terceira enzima testada foi Protamex ${ }^{\circledR}$ que é uma enzima proteolítica produzida por fermentação submersa de Bacillus licheniformes e Bacillus amyloliquefaciens com atividade declarada de 1,5 AU-NH/g. As duas últimas enzimas mencionadas foram fornecidas pela Novozymes Latin America Ltda.

\subsection{Composição proximal da matéria-prima e dos hidrolisados liofilizados}

A composição proximal da carcaça manualmente desossada de frango (CMD) e dos diferentes hidrolisados obtidos foi determinada de acordo com a metodologia recomendada pela AOAC (CUNNIFF, 1995). A quantidade de proteína presente foi determinada pelo método de determinação de nitrogênio total, Kjeldahl $(N \times 6,25)$; lipídeos pelo método gravimétrico de extração a quente utilizando extrator de Soxhlet para a CMD e o método do Bligh e Dyer (1959) para os hidrolisados liofilizados; cinzas pelo método gravimétrico em mufla $\left(550-600^{\circ} \mathrm{C}\right) \mathrm{e}$ a umidade pelo método gravimétrico em estufa $\left(105^{\circ} \mathrm{C}\right)$. Para a realização do cálculo do valor calórico total, foram utilizados valores de conversão, alimento/energia, sendo 4, 9 e 4 para carboidratos, lipídeos e proteínas, respectivamente, e, a seguir, foi realizado o somatório desses valores.

\subsection{Processo de obtenção do hidrolisado proteico}

\subsubsection{Condições de hidrólise}

Para a realização do processo de hidrólise, foram utilizados $250 \mathrm{~g}$ de carcaça manualmente desossada (CMD) /g ou $\mathrm{mL}$ de enzima acrescidos de $500 \mathrm{~mL}$ de água destilada (1:2) previamente aquecida e colocados em banho termostatizado (Banho Ultratermostatizado Marconi modelo MA 184). As reações enzimáticas foram conduzidas à temperatura e pH de máxima atividade catalítica de cada enzima de acordo com a literatura e estão descritas na Tabela 1 (OGAWA; MAIA, 1999; CÂNDIDO; SGARBIERI, 2003). O pH das enzimas Flavourzyme e Protamex foi ajustado com solução de fosfato de sódio 0,2 M. Durante a hidrólise, as amostras foram continuamente agitadas com agitador mecânico (Agitador Marconi modelo MA 039) durante todo o tempo de hidrólise (120 minutos).

Durante a hidrólise da CMD, caldos de amostras foram coletados aos 60 e 120 minutos de hidrólise. Todos os hidrolisados coletados foram filtrados em uma tela plástica com abertura de malha de 10 mesh, filtrados novamente em uma gaze e, a seguir, centrifugados a 4000 rpm por 10 minutos em uma centrífuga (Cetribio-Servilab) para remover todas as partículas sólidas (fundo) e a gordura (camada superior).

Depois da hidrólise, os resíduos ósseos foram pesados para a realização do cálculo de percentual de hidrólise.

A proteína hidrolisada foi então aquecida a $95^{\circ} \mathrm{C}$ por 15 minutos para inativar a enzima e, em seguida, foi

Tabela 1. Sistemas de hidrólise enzimática.

\begin{tabular}{|c|c|c|c|c|}
\hline Enzimas & {$[E]:[S]^{a}$} & $\mathbf{p H}^{\mathbf{b}}$ & Temperatura $\left({ }^{\circ} \mathbf{C}\right)^{c}$ & Tempo $(\mathrm{min})^{\mathrm{d}}$ \\
\hline Papaína & $1: 250$ & 6,5 & 60 & 120 \\
\hline Flavourzyme & $1: 250$ & 7,0 & 50 & 120 \\
\hline Protamex & $1: 250$ & 7,0 & 50 & 120 \\
\hline
\end{tabular}

aRelação Enzima/Substrato (p/p). ${ }^{\mathrm{p} p H}$ ótimo de ação das enzimas. ${ }^{\circ}$ Temperatura ótima de ação das enzimas. ${ }^{\mathrm{d} T e m p o}$ total de hidrólise. Fonte: Ogawa e Maia (1999), Cândido e Sgarbieri (2003). 
Utilização de enzimas proteolíticas para produção de hidrolisados proteicos a partir de carcaças de frango desossadas manualmente

OLIVEIRA, M. S. R. et al.

resfriada à temperatura ambiente, congelada e, então, liofilizada a uma temperatura de $-54{ }^{\circ} \mathrm{C}$ em liofilizador (LD 1500 Terroni).

\subsubsection{Determinação do Grau de Hidrólise (GH)}

Alíquotas de hidrolisado durante os tempos indicados foram retiradas e a reação foi inativada com adição de uma solução de ácido tricloroacético (TCA) 10\%. Depois de repouso de 10 minutos e filtração para a remoção do material insolúvel precipitado pelo TCA, as proteínas solúveis foram quantificadas pelo método de Lowry et al. (1951), expresso em mg de albumina. As leituras das amostras foram realizadas em espectrofotômetro (Modelo SP-220-Biospectro) a 650 nm. O grau de hidrólise foi medido segundo método descrito por Hoyle e Merritt (1994) e por Liceaga-Gesualdo e Li-Chan (1999), sendo expresso como percentagem de proteínas solúveis no TCA em relação à quantidade de proteína inicial total, e calculado em $\mathrm{mg} / \mathrm{g}$, segundo a Equação 1.

$$
\text { GH }=\frac{\text { Proteína Solúvel em } \text { TCA } 10 \% \times 100}{\text { Proteína Total da Amostra }}
$$

\subsubsection{Determinação do teor de sólidos, cinzas e proteínas totais}

Durante a hidrólise proteica foram retiradas alíquotas de amostras como mencionado no processo de obtenção de hidrólise e após a inativação enzimática foram encaminhadas para as análises de determinação do teor de sólidos solúveis totais em estufa a $105^{\circ} \mathrm{C}$, de cinzas em mufla a $550{ }^{\circ} \mathrm{C}$ e proteínas solúveis pelo método de Kjeldhal.

\subsubsection{Determinação do percentual de hidrólise e do rendimento da hidrólise}

O percentual de hidrólise (o quanto de carne foi retirada da carcaça) foi avaliado por diferença de peso da carcaça manualmente desossada (CMD) antes e depois do tempo de hidrólise de 60 minutos e 120 minutos. Para o cálculo do rendimento do hidrolisado liofilizado, fez-se uma proporção da quantidade total de amostra (CMD) em relação ao hidrolisado liofilizado obtido.

\subsection{Determinação dos aminoácidos dos hidrolisados proteicos}

As proteínas constituintes das amostras foram hidrolisadas com $\mathrm{HCl} 6 \mathrm{~N}$ durante 24 horas a $110{ }^{\circ} \mathrm{C}$. Os aminoácidos liberados durante a hidrólise ácida reagem com Fenilisotilcianato (PITC), separados por Cromatografia Líquida de Alta Eficiência (CLAE) em fase reversa e detectados por ultravioleta (UV). A quantificação foi feita por calibração interna multinível segundo a metodologia descrita por LAMIC (2012).

\subsection{Análise objetiva da cor dos hidrolisados proteicos}

A avaliação objetiva da cor dos hidrolisados obtidos foi realizada através do sistema CIE, utilizando-se o aparelho Minolta Chroma Meter, CR-300 (MINOLTA), através dos parâmetros L* (luminosidade), a* (direção para o vermelho) e $b^{\star}$ (direção para o amarelo), segundo ANSORENA et al. (1997). Minolta Chroma Meter CR-300 usa iluminação difusa (lâmpada de xenônio) e um ângulo de observação de $0^{\circ} \mathrm{C}$. A calibração do aparelho foi feita com o disco branco, sendo que tanto a leitura de $L$ (brilho) como das cores, do vermelho (a) ao verde e do amarelo (b) ao azul, foram realizadas à temperatura ambiente.

\subsection{Determinação da atividade de água}

Para a determinação da atividade de água (Aa), foi utilizado o aparelho Aqualab ${ }^{\circledR}$ modelo CX-2 (DECAGON DECIVE, 2003), para a realização da leitura direta.

\subsection{Análise estatística}

Os resultados foram avaliados estatisticamente mediante a Análise de Variância (ANOVA) e as médias comparadas entre si através do teste de Tukey ao nível de $5 \%$ de significância pelo Sistema IBM ${ }^{\circledR}$ SPSS ${ }^{\circledR}$ Statistcs (Versão 20).

\section{Resultados e discussão}

\subsection{Composição proximal da matéria-prima utilizada na hidrólise e dos hidrolisados liofilizados}

A Tabela 2 mostra as características da matériaprima utilizada no experimento (CMD). Na Tabela Brasileira de Composição de Alimentos-TACO (UNICAMP, 2011), os valores encontrados foram diferentes dos valores citados para a amostra de frango cru inteiro com pele, cujos valores são de $66,5 \%$ de umidade, $16,4 \%$ de proteína, $17,3 \%$ de lipídeos e $0,7 \%$ de cinzas. Os dados

Tabela 2. Média da composição proximal e valor calórico da carcaça manualmente desossada (CMD) utilizada no experimento.

\begin{tabular}{cc} 
Componente (b.u.) & $\begin{array}{c}\text { Carcaça Manualmente } \\
\text { Desossada (CMD) }\end{array}$ \\
\hline Umidade (\%) & $58,87 \pm 0,19$ \\
Cinzas (\%) & $0,63 \pm 0,05$ \\
Lipídeos (\%) & $26,79 \pm 4,00$ \\
Proteínas (\%) & $13,25 \pm 0,48$ \\
Carboidratos (\%) & $0,46 \pm 0,05$ \\
Valor calórico (kcal/100g) & $295,95 \pm 2,62$ \\
\hline
\end{tabular}


apresentados neste trabalho estão próximos aos relatados por Trindade et al. (2004), para CMS de galinha, em que citam várias composições centesimais de carne mecanicamente separada de frangos e galinhas. O teor de lipídeos apresentado na Tabela 2 pode ser explicado pela utilização de pele e de todas as gorduras corporais que a carcaça apresentava. Ao se comparar a carne retirada manualmente da carcaça resultante da desossa manual, verificou-se que esta possui uma composição diferenciada da carne mecanicamente separada. Gonçalves et al. (2009) analisaram 20 amostras de CMS de frango e encontraram valores médios de $16 \%$ de proteína, $17 \%$ de lipídeos, $61 \%$ de umidade e 1,17\% de cinzas. A diferença pode estar relacionada ao tipo de corte utilizado e também ao processo empregado na obtenção da CMS, pois a fabricação de CMS pode ser realizada com várias partes da carcaça. Quando são utilizadas partes do peito, o produto obtido é de melhor qualidade. O processo também influencia, pois o sistema hollow drum (tambor oco) é melhor que o sistema auger (rosca sem fim), já que com este processo o produto caracteriza-se pelo alto conteúdo de cálcio e de fragmentos de ossos e cartilagens (HENCKEL et al., 2004).

A composição química dos alimentos tem um importante papel no fornecimento de nutrientes essenciais para a manutenção da saúde humana. A Tabela 3 apresenta os dados da composição proximal dos hidrolisados obtidos da CMD com as diferentes enzimas proteolíticas. O teor de umidade foi significativamente diferente $(p<0,05)$ entre os hidrolisados liofilizados obtidos, os quais variaram de $4,58 \%$ a $8,51 \%$. A maioria dos estudos realizados com proteína hidrolisada de peixes apresenta teores de umidade inferiores a 10\% (OVISSIPOUR et al., 2009; CHALAMAIAH et al., 2010; FOH et al., 2011). Os baixos percentuais de umidade apresentados pelos hidrolisados proteicos são determinados pelas metodologias de secagem, assim como pelo tipo de amostra empregada (BUENO-SOLANO et al., 2009).

O teor de cinzas foi significativamente diferente $(p<0,05)$ entre os hidrolisados obtidos e variaram de $4,81 \%$ a $12,86 \%$ (Tabela 3 ). Os teores maiores de cinzas apresentados pelos hidrolisados obtidos com a Flavourzyme e Protamex justificam-se pelo emprego da solução de fosfato de sódio 0,2 M para o ajuste de pH.
O conteúdo de lipídeos não variou entre os hidrolisados obtidos com a Papaína e Flavourzyme, mas estes foram significativamente diferentes $(p<0,05)$ do hidrolisado obtido com a enzima Protamex, porém todos se apresentaram menores que o teor de lipídeos da matéria-prima inicial (CMD). Rossi et al. (2009), ao hidrolisarem carne mecanicamente separada de frango com a enzima Alcalase 2,4 L FG, obtiveram um hidrolisado com $1,08 \%$ de lipídeos, indicando que o processo de retirada da gordura na centrifugação foi extremamente eficiente.

Os teores de proteínas (Tabela 3) apresentados pelos hidrolisados proteicos obtidos pela hidrólise com a enzima Flavourzyme e Protamex foram semelhantes, porém diferiram $(p<0,05)$ significativamente do resultado obtido com a Papaína. A composição química do hidrolisado obtido com a Papaína assemelhou-se aos resultados obtidos por Fonkwe e Singh (1996), que obtiveram aproximadamente $78 \%$ de proteínas em uma hidrólise do resíduo da carne mecanicamente separada de peru. Já os resultados apresentados por Rossi et al. (2009) assemelham-se aos obtidos neste estudo para as enzimas Flavourzyme e Protamex.

Os teores de proteínas apresentados pelos hidrolisados obtidos com as diferentes enzimas proteolíticas são maiores que os apresentados pela matéria-prima inicial utilizada neste experimento. O procedimento normal de utilização destas carcaças gera a carne mecanicamente separada de frango (CMS), cujos teores proteicos são de aproximadamente 13\% (BRASIL, 2000). Com este processo de hidrólise enzimática, tem-se a produção de um hidrolisado em pó com grandes possibilidades de uso tanto pela indústria de alimentos como pela indústria farmacêutica para a produção de produtos geriátricos, dietas para controle de peso, terapêuticas ou dietas entéricas, além de suplementos energéticos para atletas.

Chalamaiah et al. (2012) realizaram uma extensa revisão bibliográfica, nela estão reunidos dados da composição proximal dos hidrolisados proteicos de diversas espécies de peixes, obtidos com as mais diferentes enzimas proteolíticas, porém não são comuns dados na literatura sobre hidrolisados proteicos obtidos a partir do residual ósseo gerado da desossa manual de carne de frango.

Tabela 3. Composição proximal dos hidrolisados liofilizados de carcaça manualmente desossada (CMD) obtidos através da hidrólise com diferentes enzimas.

\begin{tabular}{cccccc}
\hline Enzima & Umidade (\%) & Cinzas (\%) & Lipídeos (\%) & Proteína (\%) & Valor CAL (kcal/100g) \\
Papaína & $4,58^{\mathrm{c}} \pm 0,15$ & $4,81^{\mathrm{c}} \pm 0,03$ & $6,81^{\mathrm{a}} \pm 0,63$ & $79,36^{\mathrm{a}} \pm 0,32$ & $396,47^{\mathrm{a}} \pm 2,69$ \\
Flavourzyme & $8,51^{\mathrm{a}} \pm 0,24$ & $12,86^{\mathrm{a}} \pm 0,06$ & $5,45^{\mathrm{a}} \pm 0,47$ & $67,86^{\mathrm{b}} \pm 0,66$ & $341,79^{\mathrm{b}} \pm 2,44$ \\
Protamex & $6,23^{\mathrm{b}} \pm 0,31$ & $11,07^{\mathrm{b}} \pm 0,09$ & $3,27^{\mathrm{b}} \pm 0,97$ & $68,21^{\mathrm{b}} \pm 0,62$ & $347,12^{\mathrm{b}} \pm 3,42$ \\
\hline
\end{tabular}

Médias dentro da mesma coluna, com letras diferentes são significativamente diferentes, no nível de 5\%, pelo teste de Tukey. Resultados em b.s. 
Utilização de enzimas proteolíticas para produção de hidrolisados proteicos a partir de carcaças de frango desossadas manualmente

OLIVEIRA, M. S. R. et al.

\subsection{Grau de Hidrólise (GH)}

O grau de hidrólise fornece uma ideia do mensuramento da extensão da proteína clivada, o que vai influenciar as propriedades funcionais destes hidrolisados (LICEAGA-GESUALDO; LI-CHAN, 1999). Os resultados obtidos para o grau de hidrólise, utilizando-se como enzimas proteolíticas Papaína, Flavourzyme e Protamex e como substrato a carcaça manualmente desossada (CMD) de frango, estão apresentados na Tabela 4. No final da hidrólise (120 minutos), observam-se valores de $43 \%, 20 \%$ e $51 \%$ de GH para a Papaína, Flavourzyme e Protamex, respectivamente. Com o mesmo substrato e a mesma quantidade de enzima, o GH apresentado pela Protamex foi significativamente maior $(p<0,05)$ que o da Papaína e Flavourzyme.

Herpandi et al. (2012) utilizaram diferentes enzimas proteolíticas (Alcalase ${ }^{\circledR} 2.4 \mathrm{~L} F \mathrm{FG}$, Protamex ${ }^{\circledR}$, Neutrase ${ }^{\circledR} 1,5 \mathrm{mg}$ e Flavourzyme ${ }^{\circledR} 500 \mathrm{mg}$ ) para hidrolisar atum (Katsuwonus pelamis) e constataram que a Alcalase ${ }^{\circledR}$ 2.4L FG apresentou o maior grau de hidrólise entre todas as proteases, seguido da Protamex ${ }^{\circledR}$, Flavourzyme 500MG ${ }^{\circledR}$ e Neutrase ${ }^{\circledR} 1,5$ mg.

Charoenphun et al. (2013) utilizaram diferentes enzimas, entre elas a Papaína e a Flavourzyme, e obtiveram graus de hidrólise de $41,6 \%$ e $35,6 \%$, respectivamente, após 6 horas de hidrólise de tilápia (Oreochromis niloticus). Mesmo utilizando matérias-primas diferentes, o resultado para a Papaína assemelha-se muito com o encontrado neste estudo no tempo de 60 minutos, indicando que talvez não fosse necessário um tempo tão longo de hidrólise para esta protease. Entretanto, os resultados apresentados para a Flavourzyme foram extremamente maiores, indicando que esta exopeptidase necessita de um tempo maior para obter melhores resultados de hidrólise para esta enzima.

No entanto, Santos (2006), que analisou o grau de hidrólise obtido com a enzima Flavourzyme na elaboração de hidrolisado de Cabrinha (Prionotus punctatus) com uma concentração substrato/tampão de $1 \mathrm{~g} / \mathrm{mL} ; 2 \%$ de enzima/substrato; pH 7 e 60 minutos de reação a $50{ }^{\circ} \mathrm{C}$, encontrou um grau de hidrólise de $24,7 \%$, utilizando uma concentração de enzima/ substrato bem maior que a empregada no presente estudo.

Como pode ser observado na Tabela 4, o tempo influencia positivamente o grau de hidrólise, isto está de acordo com o trabalho realizado por Schmidt e Salas-Mellado (2009), que obtiveram um efeito positivo para esta variável em um trabalho sobre a influência da ação das enzimas Alcalase e Flavourzyme no grau de hidrólise das proteínas de carne de frango. Também Liceaga-Gesualdo e Li-Chan (1999) observaram uma hidrólise rápida de carne de arenque (Clupea harengus), atingindo um $\mathrm{GH}$ de $24 \%$ em 20 minutos de incubação com a enzima Alcalase, a pH 8,0 e $50^{\circ} \mathrm{C}$, sendo que, após 60 minutos de incubação, o grau de hidrólise aumentou para $36 \%$

\subsection{Teor de proteínas solúveis, sólidos totais e cinzas durante o tempo de hidrólise}

Na Tabela 5, são apresentados os valores do teor de proteínas durante o tempo total de hidrólise para as três enzimas utilizadas no experimento. A enzima Papaína, aos 120 minutos de hidrólise, apresentou o maior percentual de proteínas, diferindo estatisticamente $(p<0,05)$ da Protamex.

Os teores de proteínas obtidos neste estudo com as enzimas proteolíticas são semelhantes aos relatos de muitas pesquisas feitas com hidrolisados obtidos de diferentes espécies de peixes que variaram de $60 \%$ a 90\% da composição total (DONG et al., 2005; CHOI et al., 2009; KHANTAPHANT et al., 2011). Os altos teores de proteínas apresentados neste trabalho demonstram que estes hidrolisados possuem grande potencial para serem utilizados como suplementos proteicos na nutrição humana.

$\mathrm{Na}$ Tabela 6, podem ser observados os valores dos teores de sólidos solúveis de hidrolisados de CMD de frango e da atividade de água dos hidrolisados liofilizados obtidos durante o tempo de hidrólise para as três enzimas proteolíticas utilizadas.

Os teores de sólidos solúveis totais (Tabela 6) nos tempos de 60 e 120 minutos de hidrólise não apresentaram diferenças significativas $(p>0,05)$ entre

Tabela 4. Grau de hidrólise apresentado durante 60 e 120 minutos de hidrólise para as diferentes enzimas utilizadas em condições estabelecidas de $\mathrm{pH}$ e temperatura.

\begin{tabular}{lcc}
\multirow{2}{*}{ Enzimas } & \multicolumn{2}{c}{ Grau de Hidrólise ( $\mathbf{m g} / \mathbf{g})$} \\
\cline { 2 - 3 } & $\mathbf{6 0} \mathbf{~} \mathbf{~ i n}$ & $\mathbf{1 2 0} \mathbf{~ m i n}$ \\
\hline Papaína & $39,25^{\mathrm{b}} \pm 4,97$ & $43,19^{\mathrm{b}} \pm 4,69$ \\
Flavourzyme & $16,72^{\mathrm{c}} \pm 1,89$ & $20,25^{\mathrm{c}} \pm 4,33$ \\
Protamex & $47,12^{\mathrm{a}} \pm 5,27$ & $51,31^{\mathrm{a}} \pm 4,61$ \\
\hline
\end{tabular}

Médias dentro da mesma coluna, com letras diferentes são significativamente diferentes, no nível de 5\%, pelo teste de Tukey.

Tabela 5. Teor de proteínas dos hidrolisados obtidos de carcaça manualmente desossada (CMD) de frango durante o tempo de hidrólise de 120 minutos com diferentes enzimas.

\begin{tabular}{lcc}
\multirow{2}{*}{\multicolumn{1}{c}{ Enzimas }} & \multicolumn{2}{c}{ Teor de Proteínas (\%) } \\
\cline { 2 - 3 } & $\mathbf{6 0} \mathbf{~} \mathbf{~ i n}$ & $\mathbf{1 2 0} \mathbf{~ m i n}$ \\
\hline Papaína & $74,37^{\mathrm{a}} \pm 10,45$ & $75,08^{\mathrm{a}} \pm 6,70$ \\
Flavourzyme & $61,58^{\mathrm{b}} \pm 9,79$ & $66,80^{\mathrm{ab}} \pm 8,87$ \\
Protamex & $63,99^{\mathrm{ab}} \pm 6,36$ & $63,96^{\mathrm{b}} \pm 5,29$ \\
\hline
\end{tabular}

Médias dentro da mesma coluna, com letras diferentes são significativamente diferentes, no nível de $5 \%$, pelo teste de Tukey. Resultados em (g/100g base seca). 
Utilização de enzimas proteolíticas para produção de hidrolisados proteicos a partir de carcaças de frango desossadas manualmente

OLIVEIRA, M. S. R. et al.

Tabela 6. Percentual de sólidos solúveis dos hidrolisados obtidos de carcaça manualmente desossada (CMD) de frango durante o tempo de hidrólise de 60 e 120 minutos com diferentes enzimas e a atividade de água dos hidrolisados liofilizados.

\begin{tabular}{lccc}
\multicolumn{1}{c}{ Enzimas } & \multicolumn{1}{c|}{ Percentual de Sólidos Solúveis } & $\begin{array}{c}\text { Atividade de água do } \\
\text { Hidrolisado Liofilizado (Aa) }\end{array}$ \\
Papaína & $\mathbf{6 0} \mathbf{~ m i n}$ & $\mathbf{1 2 0} \mathbf{m i n}$ & $\mathbf{1 2 0} \mathbf{m i n}$ \\
Flavourzyme & $7,11^{\mathrm{a}} \pm 0,74$ & $8,55^{\mathrm{a}} \pm 0,32$ & $0,1408^{\mathrm{c}} \pm 0,0123$ \\
Protamex & $5,49^{\mathrm{b}} \pm 1,10$ & $6,34^{\mathrm{b}} \pm 0,71$ & $0,2884^{\mathrm{b}} \pm 0,0178$ \\
\hline
\end{tabular}

Médias dentro da mesma coluna, com letras diferentes são significativamente diferentes, no nível de 5\%, pelo teste de Tukey. Resultados em (g/100g base úmida)

as enzimas Papaína e Protamex, porém a enzima Flavourzyme apresentou um percentual de sólidos solúveis estatisticamente menor $(p<0,05)$ que os valores obtidos com as outras duas enzimas.

Os teores de sólidos solúveis dos hidrolisados obtidos pela hidrólise realizada com as enzimas Papaína e Protamex são semelhantes aos relatados por Oliveira (1991), que, ao determinar as condições ideais da hidrólise da proteína de carne com suco de abacaxi (carne/suco 1:1), obteve um teor de sólidos de 7,6 g/100g.

Nota-se um aumento da solubilidade das proteínas durante a hidrólise e isto ocasiona um aumento da concentração dos sólidos solúveis ao longo do tempo, mas não se pode afirmar que sejam diferentes (FONKWE; SINGH, 1996).

A medida da atividade de água é de fundamental importância, para o controle de qualidade dos alimentos, visto que, por meio dela, podem ser previstas reações químicas, enzimáticas e desenvolvimento de microrganismos. A partir do conhecimento da atividade de água, pode-se, também, propor sistemas adequados de embalagens para diferentes produtos alimentícios (FELLOWS, 2006). Os hidrolisados proteicos são altamente perecíveis principalmente devido ao alto conteúdo de proteínas e, portanto, necessitam de metodologias para a sua preservação como secagem por pulverização ou liofilização.

Os valores encontrados para a atividade de água para os hidrolisados liofilizados obtidos da CMD com diferentes enzimas proteolíticas (Tabela 6) diferiram estatisticamente $(p<0,05)$ entre si. A Papaína produziu o hidrolisado liofilizado com a menor atividade de água $(0,14)$. Valor de atividade de água, maior que estes resultados, foi encontrado por Kurozawa et al. (2009), que relataram um valor de atividade de água de 0,43 ao estudarem o efeito dos agentes de suporte durante a secagem por pulverização sobre as propriedades físico-químicas de um hidrolisado proteico de carne de frango obtido pela ação da Alcalase ${ }^{\circledR} 2.4 \mathrm{~L}$.

A Tabela 7 apresenta os resultados de cinzas dos diferentes hidrolisados para os tempos de hidrólise de 60 e 120 minutos. Os resultados apresentados nos primeiros 60 minutos variaram significativamente $(p<0,05)$ e, aos 120 minutos, o hidrolisado obtido com a Papaína apresentou teores significativamente menores de cinzas $(p<0,05)$, quando comparados aos outros hidrolisados. A maior concentração de cinzas verificada nos hidrolisados obtidos com a Flavourzyme e com a Protamex (6,76\% a 7,97\%) é decorrente do ajustamento do $\mathrm{pH}$ durante a hidrólise enzimática.

Da mesma forma outros autores obtiveram níveis elevados de cinzas nos experimentos de hidrólise que foram atribuídos ao ajustamento do $\mathrm{pH}$ para uma melhor ação das enzimas (DINIZ; MARTIN, 1997; LICEAGA-GESUALDO; LI-CHAN, 1999; NEVES et al., 2004; MARTINS et al., 2009).

\subsection{Percentual de hidrólise e do rendimento da hidrólise}

Os valores dos percentuais de hidrólise após 60 e 120 minutos de processo hidrolítico e os rendimentos dos hidrolisados submetidos ao processo de liofilização estão demonstrados na Tabela 8. Depois de 60 minutos de hidrólise, todos os hidrolisados apresentaram percentuais de hidrólise significativamente diferentes entre si $(p<0,05)$, e a Papaína apresentou o maior percentual. Porém, aos 120 minutos, os hidrolisados obtidos com a Papaína e a Protamex não diferiram estatisticamente ( $p>0,05)$, enquanto o hidrolisado obtido com a Flavourzyme apresentou diferença significativa das outras enzimas, sendo o de menor percentual (58,20\%). Uma justificativa para isto poderia estar relacionada ao fato de a Papaína, uma sulfidrilo protease, ou seja, uma enzima que possui um grupo de enxofre no seu sítio ativo, apresentar baixa especificidade, hidrolisando ligações amida e éster, tanto em peptídeos como em proteínas (LIENER, 1974; REED, 1975).

O rendimento do hidrolisado liofilizado (Tabela 8) obtido aos 60 minutos pela hidrólise com a Flavourzyme diferiu significativamente $(p<0,05)$ dos hidrolisados obtidos com a Papaína e a Protamex, apresentando a mesma tendência dos resultados de percentual de hidrólise que foram obtidos aos 120 minutos. Santos (2011), em um trabalho sobre a produção de hidrolisados 
Tabela 7. Valores percentuais de cinzas dos hidrolisados obtidos com diferentes enzimas a partir de carcaça manualmente desossada (CMD) de frango com o tempo de hidrólise de 60 e 120 minutos.

\begin{tabular}{lcc}
\multirow{2}{*}{\multicolumn{1}{c}{ Enzimas }} & \multicolumn{2}{c}{ Cinzas (\%) } \\
\cline { 2 - 3 } & $\mathbf{6 0} \mathbf{~ m i n}$ & $\mathbf{1 2 0} \mathbf{~ m i n}$ \\
\hline Papaína & $4,80^{\mathrm{b}} \pm 0,36$ & $4,68^{\mathrm{b}} \pm 0,48$ \\
Flavourzyme & $7,97^{\mathrm{a}} \pm 1,44$ & $6,76^{\mathrm{a}} \pm 0,99$ \\
Protamex & $7,24^{\mathrm{a}} \pm 1,69$ & $7,08^{\mathrm{a}} \pm 1,28$ \\
\hline
\end{tabular}

Médias dentro da mesma coluna, com letras diferentes são significativamente diferentes, no nível de 5\%, pelo teste de Tukey. Resultados em (g/100g base úmida).

Tabela 8. Valores do percentual de hidrólise e do rendimento total dos hidrolisados liofilizados obtidos de carcaça manualmente desossada (CMD) de frango durante o tempo de hidrólise de 60 e 120 minutos com diferentes enzimas.

\begin{tabular}{lccc}
\multicolumn{1}{c}{ Enzimas } & \multicolumn{2}{c}{ Percentual de Hidrólise (\%) } & $\begin{array}{c}\text { Rendimento } \\
\mathbf{( \% )}\end{array}$ \\
& $\mathbf{6 0} \mathbf{~} \mathbf{m i n}$ & $\mathbf{1 2 0} \mathbf{~} \mathbf{m i n}$ & $\mathbf{1 2 0} \mathbf{~ m i n}$ \\
Papaína & $80,61^{\mathrm{a}} \pm 5,49$ & $86,13^{\mathrm{a}} \pm 2,24$ & $10,55^{\mathrm{a}} \pm 0,04$ \\
Flavourzyme & $34,83^{\mathrm{c}} \pm 5,79$ & $58,20^{\mathrm{b}} \pm 5,65$ & $4,84^{\mathrm{b}} \pm 0,46$ \\
Protamex & $67,69^{\mathrm{b}} \pm 4,12$ & $78,03^{\mathrm{a}} \pm 3,61$ & $10,32^{\mathrm{a}} \pm 0,09$ \\
\hline
\end{tabular}

Médias dentro da mesma coluna, com letras diferentes são significativamente diferentes, no nível de $5 \%$

de proteína de pescado (HPP) a partir de subprodutos da indústria pesqueira, encontrou aproximadamente $10 \%$ de rendimento utilizando como enzima proteolítica a Neutrase ${ }^{\circledR}$.

\subsection{Aminoácidos dos hidrolisados proteicos}

A Tabela 9 apresenta os valores da composição dos aminoácidos dos hidrolisados obtidos com as diferentes enzimas proteolíticas. O valor nutritivo das proteínas dietéticas é determinado pelo padrão e quantidade de aminoácidos essenciais (XIA et al, 2007).

A presença de um ou mais aminoácidos essenciais em quantidades suficientes aumenta o valor nutritivo da proteína (RANGEL et al., 2004). O perfil das proteínas dos diferentes hidrolisados foi verificado e comparado com o da FAO (1985), que estima as necessidades de aminoácidos para crianças e adultos. O perfil de aminoácidos (Tabela 9) dos hidrolisados de carne manualmente desossada de frango (CMD) obtida pela hidrólise enzimática com a Papaína continha quantidades mais elevadas de todos os aminoácidos essenciais, exceto para triptofano (eliminado pela metodologia), quando comparado com a referência da OMS para adultos. Portanto, o hidrolisado que mais se aproxima das quantidades de aminoácidos recomendados pela FAO (1985) é o obtido pela hidrólise com a Papaína.
Soares et al. (2004) utilizaram três enzimas isoladamente (uma protease do Aspergillus oryzae, a Papaína e a Pepsina) para a hidrólise de leite em pó desnatado e avaliaram a ação enzimática sobre o perfil peptídico dos hidrolisados e concluíram que o melhor perfil peptídico nutricional foi obtido com a Papaína. Morais et al. (2002) descreveram a influência da relação E:S sobre a hidrólise da caseína bovina com uso de papaína, e ressaltaram que a alteração da relação E:S de $2 \%$ para $4 \%$ alterou significativamente o conteúdo de todas as frações cromatográficas, e produziu um perfil peptídico distinto, com diminuição dos níveis de di- e tripeptídeos e aumento do teor de aminoácidos livres e de peptídeos médios. O aumento da relação E:S deveria promover a quebra dos grandes e médios peptídeos a di- e tripeptídeos, porém levou à clivagem desses a aminoácidos livres. No presente estudo a metodologia empregada não determinou o tamanho dos peptídeos originados, somente a quantificação dos aminoácidos.

As variações dos aminoácidos nos diferentes hidrolisados podem ser decorrentes da distribuição variável entre os hidrolisados e o resíduo proteico insolúvel. O tratamento térmico realizado no final do processo de hidrólise, utilizado para inativar as enzimas, também pode ter contribuído na alteração da distribuição dos aminoácidos entre a fração proteica solúvel e insolúvel (NETTO; GALEAZZI, 1998).

A análise de aminoácidos realizada por Sun et al. (2010) em um estudo sobre a utilização de um hidrolisado obtido enzimaticamente do resíduo de carne mecanicamente separada de frango, em uma salsicha tipo cantonês, revelou que a glicina foi o aminoácido encontrado em maior quantidade neste tipo de hidrolisado (21,46\%), além do ácido glutâmico, prolina, ácido aspártico, treonina e a lisina.

\subsection{Análise objetiva da cor dos hidrolisados proteicos}

Os valores da determinação da cor dos hidrolisados liofilizados obtidos com diferentes enzimas proteolíticas encontram-se na Tabela 10. Os valores de L* (brilho) e de $a^{*}$ (índice vermelho) diferiram estatisticamente $(p<0,05)$ para as três enzimas utilizadas. O parâmetro de cor vermelha $\left(a^{*}\right)$ foi maior com o hidrolisado obtido com a enzima Protamex. Segundo Bueno-Solano et al. (2009), a hidrólise de proteínas produz peptídeos com cor acastanhada que podem gerar uma alteração de cor nos produtos alimentícios nos quais estes hidrolisados são adicionados.

O parâmetro de cor amarela não variou entre os hidrolisados (Tabela 10) obtidos com a Flavourzyme e a Protamex, porém estes diferiram significativamente $(p<0,05)$ do hidrolisado obtido com a Papaína que apresentou maior intensidade para o amarelo. 
Utilização de enzimas proteolíticas para produção de hidrolisados proteicos a partir de carcaças de frango desossadas manualmente

OLIVEIRA, M. S. R. et al.

Tabela 9. Valores da composição de aminoácidos dos hidrolisados obtidos com diferentes enzimas a partir de carcaça manualmente desossada de frango (CMD) em comparação com as recomendações da FAO (1985).

\begin{tabular}{|c|c|c|c|c|c|}
\hline & \multicolumn{5}{|c|}{ Composição de Aminoácidos (mg/g) } \\
\hline & Papaína & Flavourzyme & Protamex & $\begin{array}{c}\text { FAO } \\
\text { (2-5 anos) }\end{array}$ & FAO (adultos) \\
\hline \multicolumn{6}{|c|}{ Não essenciais } \\
\hline Ácido aspártico & 73,7 & 49,6 & 62,5 & - & - \\
\hline Ácido glutâmico & 117,6 & 92,7 & 107,7 & - & - \\
\hline Serina & 30,1 & 20,6 & 25,7 & - & - \\
\hline Glicina & 52,3 & 44,1 & 46,4 & - & - \\
\hline Arginina & 54,8 & 9,90 & 46,4 & - & - \\
\hline Treonina & 28,1 & 30,1 & 26,6 & 34 & 5 \\
\hline Alanina & 46,2 & 35,5 & 43,6 & - & - \\
\hline Prolina & 43,9 & 33,4 & 37,4 & - & - \\
\hline \multicolumn{6}{|c|}{ Essenciais } \\
\hline Histidina & 22,4 & 19,5 & 20,6 & 19 & 16 \\
\hline Tirosina & 24,4 & 13,6 & 18,2 & - & - \\
\hline Valina & 36,8 & 23,3 & 28,9 & 35 & 13 \\
\hline Metionina & 37,2 & 16,2 & 30,6 & $24^{*}$ & $17^{\star}$ \\
\hline Cistina & 1,00 & 1,00 & 1,00 & - & - \\
\hline Isoleucina & 34,1 & 19,3 & 25,7 & 28 & 13 \\
\hline Leucina & 63,3 & 39,5 & 51,6 & 66 & 19 \\
\hline Fenilalanina & 39,3 & 26,2 & 34,1 & $63^{* *}$ & $19^{* *}$ \\
\hline Lisina & 76,0 & 57,8 & 71,8 & 58 & 16 \\
\hline Triptofano & - & - & - & 11 & 9 \\
\hline
\end{tabular}

${ }^{*}$ Dados que somam metionina+cistina. **Dados que somam fenilalanina+tirosina- FAO (1985).

Tabela 10. Valores médios da determinação de cor dos hidrolisados proteicos de carcaça manualmente desossada (CMD) obtidos pela hidrólise com diferentes enzimas, expressos como L* (luminosidade), a* (índice vermelho) e $b^{*}$ (índice amarelo).

\begin{tabular}{lcrc}
\multicolumn{1}{c}{ Enzimas } & \multicolumn{1}{c}{$\mathbf{L}^{*}$} & \multicolumn{1}{c}{$\mathbf{a}^{*}$} & $\mathbf{b}^{*}$ \\
\hline Papaína & $76,50^{\mathrm{b}} \pm 0,34$ & $-1,45^{\mathrm{c}} \pm 0,75$ & $26,44^{\mathrm{a}} \pm 2,96$ \\
Flavourzyme & $79,24^{\mathrm{a}} \pm 0,23$ & $2,98^{\mathrm{b}} \pm 0,07$ & $17,45^{\mathrm{b}} \pm 0,11$ \\
Protamex & $71,09^{\mathrm{c}} \pm 0,44$ & $5,04^{\mathrm{a}} \pm 0,10$ & $18,72^{\mathrm{b}} \pm 0,14$ \\
\hline
\end{tabular}

Médias dentro da mesma coluna, com letras diferentes são significativamente diferentes, no nível de $5 \%$.

Os hidrolisados liofilizados obtidos apresentaram cores suaves que podem contribuir para sua aceitabilidade, quando utilizados em formulações para as mais variadas finalidades.

Sun et al. (2010) concluíram que o hidrolisado do resíduo de carne mecanicamente separada de frango, obtido por hidrólise enzimática com Pancreatina, pode ser um excelente precursor para a reação de Maillard devido à distribuição do peso molecular, do perfil de aminoácidos e da quantidade de aminoácidos livres.

\section{Conclusão}

Os hidrolisados proteicos obtidos da carcaça manualmente desossada (CMD) de frango apresentaram alto conteúdo proteico caracterizando-se como uma matéria-prima promissora na formulação de dietas especiais. A enzima Protamex apresentou o melhor grau de hidrólise seguida da Papaína e da Flavourzyme. Quanto ao percentual de hidrólise e rendimento total, os hidrolisados obtidos com a Papaína e a Protamex apresentaram maiores valores que com a Flavourzyme. A composição de aminoácido demonstra que o hidrolisado obtido da Papaína possui uma composição mais próxima da recomendada pelos órgãos de controle que avaliam o valor nutricional de uma proteína pelos tipos de aminoácidos que a compõem.

\section{Referências}

ADLER-NISSEN, J. Enzimic hydrolysis of food proteins. Barking: Elsevier Applied Science, 1986. p. 427.

ANSORENA, D.; DE PEÑA, M. P.; ASTIASARÁN, I.; BELLO, J. Colour evaluation of chorizo de Pamplona, a Spanish dry fermented sausage: Comparison between the $\mathrm{CIE} \mathrm{L}^{*} \mathrm{a}^{*} \mathrm{~b}^{*}$ and the Hunter Lab systems with illuminants D 65 and C . Meat Science, Barking, v. 46, n. 4, p. 313-318, 1997. http://dx.doi.org/10.1016/ S0309-1740(97)00025-9. PMid:22062314.

BELUSSO, D.; HESPANHOL, A. N. A evolução da avicultura industrial brasileira e seus efeitos territoriais. Revista Percurso - NEMO, Maringá, v. 2, n. 1, p. 25-51, 2010. 
Utilização de enzimas proteolíticas para produção de hidrolisados proteicos a partir de carcaças de frango desossadas manualmente

OLIVEIRA, M. S. R. et al.

BHASKAR, N.; MODI, V. K.; GOVINDARAJU, K.; RADHA, C.; LALITHA, R. G. Utilization ofmeat industry by products: protein hydrolysate from sheep visceral mass. Bioresource Technology, Barking, v. 98, n. 2, p. 388-394, 2007. http://dx.doi. org/10.1016/j.biortech.2005.12.017. PMid:16457999.

BLIGH, E. G.; DYER, W. J. A rapid method of total lipid extraction and purification. Canadian Journal of Biochemistry and Physiology, Ottawa, v. 37, n. 8, p. 911-917, 1959. PMid:13671378.

BRASIL. Ministério da Agricultura e Abastecimento. Secretaria de Defesa Agropecuária. Instrução normativa N 4, de 31 de março de 2000. Regulamento técnico para fixação de identidade e qualidade de carne mecanicamente separada (CMS) de aves, bovinos e suínos. Diário Oficial [da] República Federativa do Brasil, Brasília, DF, 05 abr. 2000. p. 6-7.

BRASIL. Ministério da Agricultura, Pecuária e Abastecimento - MAPA. Relatório de avaliação dos objetivos setoriais e dos programas do plano plurianual 2008-2011. Brasília, DF: MAPA, 2011

BUENO-SOLANO, C.; LOPEZ-CERVANTES, J.; CAMPASBAYPOLI, O. N.; LAUTERIO GARCIA, R.; ADAN-BANTE, N. P.; SANCHEZ-MACHADO, D. I. Chemical and biological characteristics of protein hydrolysates from fermented shrimp by-products. Food Chemistry, London, v. 112, n. 3, p. 671-675, 2009. http://dx.doi.org/10.1016/j.foodchem.2008.06.029.

CÂNDIDO, L. M. B.; SGARBIERI, V. C. A hidrólise enzimática de tilápia do Nilo(Oreochromus niloticus) proteínas miofibrilares: efeitos sobre propriedades nutricionais e hidrofílico. Journal of the Science of Food and Agriculture, London, v. 83, p. 937-944, 2003.

CHALAMAIAH, M.; KUMAR, B. D.; HEMALATHA, R.; JYOTHIRMAYI, T. Fish protein hydrolysates: proximate composition, amino acid composition, antioxidant activities and applications: a review. Food Chemistry, London, v. 135, n. 4, p. 3020-3038, 2012. http://dx.doi.org/10.1016/j. foodchem.2012.06.100. PMid:22980905.

CHALAMAIAH, M.; RAO, G. N.; RAO, D. G.; JYOTHIRMAYI, T. Proteinhydrolysates from meriga (Cirrhinus mrigala) egg and evaluation of their functional properties. Food Chemistry, London, v. 120, n. 3, p. 652-657, 2010. http://dx.doi.org/10.1016/j. foodchem.2009.10.057.

CHAROENPHUN, N.; CHEIRSILP, B.; SIRINUPONG, N.; YOURAVONG, W. Calcium-binding peptides derived from tilapia (Oreochromis niloticus) protein hydrolysates. European Food Research and Technology, Berlin, v. 236, n. 1, p. 57-63, 2013. http://dx.doi.org/10.1007/s00217-012-1860-2.

CHOI, Y. J.; HUR, S.; CHOI, B. D.; KONNO, K.; PARK, J. W. Enzymatic hydrolysis of recovered protein from frozen small croaker and functional properties of its hydrolysates. Journal of Food Science, Champaign, v. 74, n. 1, p. C17-C24, 2009. http:// dx.doi.org/10.1111/j.1750-3841.2008.00988.x. PMid:19200081.
CUNNIFF, P. (Ed.). Official methods of analysis of the Association of Official Analytical Chemists. 16. ed. Washington: AOAC, 1995.

DECAGON DEVICES. AquaLab - Water Activity Meter: operator's manual. Version 2.0. Pullman, 2003.

DINIZ, F. M.; MARTIN, A. M. Optimization of nitrogen recovery in the enzymatic hydrolysis of dogfish (Squalus acanthias) protein. Composition of the hydrolysates. Int. International Journal of Food Sciences and Nutrition, Basingstoke, v. 48, n. 3, p. 191-200, 1997. PMid:9205594.

DONG, Y.; SHENG, G.; FU, J.; WEN, K. Chemical characterization and antianaemia activity of fish protein hydrolysate from Saurida elongate. Journal of the Science of Food and Agriculture, London, v. 85, n. 12, p. 2033-2039, 2005. http://dx.doi. org/10.1002/jsfa.2219.

FELLOWS, P. J. Tecnologia do processamento dos alimentos: príncipios e práticas. 2. ed. Porto Alegre: Artmed, 2006. 602 p.

FOH, M. B. K.; KAMARA, M. T.; AMADOU, I.; FOH, B. M.; WENSHUI, X. Chemical and physicochemical properties of Tilapia (Oreochromis niloticus) fish protein hydrolysates and concentrate. International Journal of Biological Chemistry, Pakistan, v. 5, n. 1, p. 21-36, 2011. http://dx.doi.org/10.3923/ ijbc.2011.21.36.

FONKWE, L. G.; SINGH, R. K. Protein recovery from mechanically Deboned Turkey residue by Enzymic Hydrolysis. Process Biochemistry, Watford, v. 6, p. 605-616,1996.

FOOD AND AGRICULTURE ORGANIZATION - FAO. Energy and protein requirements. Report of a joint FAO/WHO/ UNU Expert Consultation. Geneve: World Health Organization, 1985.

GONÇALVES, R. M., GONÇALVES, J. R.; GONÇALVES, R. M.; OLIVEIRA, R. R.; OLIVEIRA, R. A.; LAGE, M. E. Avaliação físico-química e conteúdo de metais pesados em carne mecanicamente separada (CMS) de frango e de bovino produzidas no estado de Goiás. Ciência Animal Brasileira, Goiânia, v. 10, n. 2, p. 553-559, 2009.

HENCKEL, P.; VYBERG, M.; THODE, S.; HERMANSEN, S. Assessing the quality of mechanically and manually recovered chicken meat. Lebensmittel-Wissenschaft \& Technologie =Food Science and Technology, London, v. 37, p. 593-601, 2004.

HERPANDI, HUDA, N.; ROSMA, A.; WAN NADIAH, W. A. Degree of hydrolysis and free tryptophan content of Skipjack Tuna (Katsuwonus pelamis) protein hydrolysates produced with different type of industrial proteasesInternational. Food Research Journal, Toronto, v. 19, n. 3, p. 863-867, 2012.

HOYLE, N. T.; MERRITT, J. H. Quality of fish protein hydrolysate from herring (Clupea harengus). Journal of Food Science, Chicago, v. 59, n. 1, p. 76-79, 1994. http://dx.doi. org/10.1111/j.1365-2621.1994.tb06901.x. 
Utilização de enzimas proteolíticas para produção de hidrolisados proteicos a partir de carcaças de frango desossadas manualmente

OLIVEIRA, M. S. R. et al.

KHANTAPHANT, S.; BENJAKUL, S.; KISHIMURA, H. Antioxidative and ACE inhibitor activities of protein hydrolysates from the muscle of brownstripe red snapper prepared using pyloric caeca and commercial proteases. Process Biochemistry, London, v. 46, n. 1, p. 318-327, 2011. http://dx.doi.org/10.1016/j. procbio.2010.09.005

KUROZAWA, L. E.; PARK, K. J.; HUBINGER, M. D. Effect of carrier agents on the physicochemical properties of a spray dried chicken meat protein hydrolysate. Journal of Food Engineering, Essex, v. 94, n. 3-4, p. 326-333, 2009. http://dx.doi. org/10.1016/j.jfoodeng.2009.03.025

LABORATÓRIO DE ANÁLISES MICOTOXICOLÓGICAS - LAMIC. Metodologias do LAMIC. Santa Maria: Universidade Federal de Santa Maria, 2012. Disponível em: <http://www.lamic.ufsm. br/web/>. Acesso em: 20 nov. 2012

LAHL, W. J.; BRAUN, S. D. Enzymatic production of protein hydrolysates for food use. Food Technology, Chicago, v. 48, n. 10, p. $68-71,1994$

LICEAGA-GESUALDO, A. M.; LI-CHAN, E. C. Y. Functional properties of fish protein hydrolysate from herring (clupea harengus). Journal of Food Science, Chicago, v. 64, n. 6, p. 1000-1004, 1999. http://dx.doi.org/10.1111/j.1365-2621.1999. tb12268.x.

LIENER, I. E. The sulfhydryl proteases. In: WHITAKER, J. R. (Ed.). Food related enzymes. Washington: American Chemistry Society, 1974. p. 202-219. (Advances in Chemistry Series, 136).

LOWRY, O. H.; ROSEBROUGH, N. J.; FARR, A. L.; RANDALL, R. J. Protein measurement with the Folin Fhenol reagent. Journal of Biological Chemistry, Bethesda, v. 193, n. 1, p. 265-275, 1951. PMid:14907713.

MARTINS, V. G.; COSTA, J. A. V.; PRENTICE-HERNÁNDEZ, C. Hidrolisado protéico de pescado obtido por vias química e enzimática a partir de corvina (Micropogonias furnieri). Quimica Nova, São Paulo, v. 32, n. 1, p. 61-66, 2009. http://dx.doi. org/10.1590/S0100-40422009000100012.

MORAIS, H. A.; BARBOSA, C. M. S.; LOPES, D. C. F.; OLIVEIRA, M. C.; SILVESTRE, M. P. C. Caracterização do perfil peptídico e de aminoácidos em hidrolisados da caseína. Archivos Latinoamericanos de Nutricion, Caracas, v. 52, n. 1, p. 77-83, 2002. PMid:12214552.

MUSSATTO, S. I.; FERNANDES,M.; MILAGRES,A.M.F. Biotecnologia - enzimas ferramentas na indústria. Ciência Hoje, Rio de Janeiro, v. 41, n. 242, p. 28-33, 2007.

NETTO, F. M.; GALEAZZI, M. A. M. Production and characterization of enzymatic hydrolysate from soy protein isolate. LebensmittelWissenschaft \& Technologie =Food Science and Technology, London, v. 31, p. 624-631, 1998.

NEVES, R. A. M.; MIRA, N. V. M.; MARQUEZ, U. M. L. Caracterização de hidrolisados enzimáticos de pescado. Ciência e Tecnologia de Alimentos, Campinas, v. 24, n. 1, p. 101-108, 2004. http://dx.doi.org/10.1590/S0101-20612004000100019.

OGAWA, N. B. P.; MAIA, E. L. Manual de pesca: ciência e tecnologia do pescado. São Paulo: Varela, 1999. 430 p.

OLIVEIRA, M. N. Otimização do processo biotecnológico de hidrólise de carne bovina. 1991. 193 f. Tese (Doutorado em Tecnologia de Alimentos)-Faculdade de Ciências Farmacêuticas, Universidade de São Paulo, São Paulo, 1991.

OLIVEIRA, M. S. R.; FRANZEN, F. L.; TERRA, N. N. Utilização da carne mecanicamente separada de frango para a produção de hidrolisados proteicos a partir de diferentes enzimas proteolíticas. Semina: Ciências Agrárias, Londrina, v. 35, n. 1, p. 291-302, 2014.

OLIVO, R. O mundo do frango: cadeia produtiva da carne de frango. Criciúma: Varela, 2006.

OVISSIPOUR, M.; ABEDIAN, A.; MOTAMEDZADEGAN, A.; RASCO, B.; SAFARI, R.; SHAHIRI, H. The effect of enzymatic hydrolysis time and temperatureon the properties of protein hydrolysates from Persian sturgeon (Acipenser persicus) viscera. Food Chemistry, London, v. 115, n. 1, p. 238-242, 2009. http://dx.doi.org/10.1016/j.foodchem.2008.12.013.

RANGEL, A.; SARAIVA, K.; SCHWENGBER, P.; NARCISO, M.; DOMONT, G.; FERREIRA, S.; PEDROSA, C. Biological evaluation of a protein isolate from cowpea (Vigna unguiculata) seeds. Food Chemistry, London, v. 87, n. 4, p. 491-499, 2004. http://dx.doi. org/10.1016/j.foodchem.2003.12.023.

REED, G. Enzymes in food processing. 2. ed. New York: Academic Press, 1975. 573 p.

ROSSI, D. M.; FLÔRES, S. H.; VENZKE, J. G.; AYUB, M. A. Z. Biological evaluation of mechanically deboned chicken meat protein hydrolysate. Revista de Nutrição, Campinas, v. 22, n. 6, p. 879-885, 2009.

SANTOS, M. F. G. Produção de hidrolisados de proteína de pescado (HPP) a partir de subprodutos da indústria do pescado de Peniche - aplicações. 2011. 69 f. Dissertação (Mestrado em Biotecnologia dos Recursos Marinhos)-Escola Superior de Turismo e Tecnologia do Mar, Instituto Politécnico de Leiria, Peniche, 2011.

SANTOS, S. D. Obtenção e avaliação de hidrolisado enzimático obtido a partir de pescado de baixo valor comercial. 2006. 110 f. Dissertação (Mestrado em Engenharia e Ciência de Alimentos)-Universidade Federal do Rio Grande, Rio Grande, 2006.

SCHMIDT, C. G.; SALAS-MELLADO, M. Influência da ação das enzimas Alcalase e Flavourzyme no grau de hidrólise das proteínas de carne de frango. Quimica Nova, São Paulo, v. 32, n. 5, p. 1144-1150, 2009. http://dx.doi.org/10.1590/S010040422009000500012. 
Utilização de enzimas proteolíticas para produção de hidrolisados proteicos a partir de carcaças de frango desossadas manualmente

OLIVEIRA, M. S. R. et al.

SLIZYTE, R.; DAUKSAS, E.; FALCH, E.; STORRO, I.; RUSTAD, T. Characteristics of protein fractions generated from hydrolysed cod (Gadus morhua) by-products. Process Biochemistry, London, v. 40, n. 1, p. 2021-2033, 2005. http://dx.doi. org/10.1016/j.procbio.2004.07.016.

SOARES, R. D. L.; SILVA, V. D. M.; LOPES, D. C. F.; JUNQUEIRA, R. G. A., et al. Perfil peptídico de hidrolisados enzimáticos de leite em pó desnatado Revista Brasileira de Ciências Farmacêuticas. Brazilian Journal of Pharmaceutical Sciences, São Paulo, v. 40, n. 3, p. 353-362, 2004.

SUN, W.; ZHAO, M.; CUI, C.; ZHAO, Q.; YANG, B. Effect of Maillard reaction products derived from the hydrolysate of mechanically deboned chicken residue on the antioxidant, textural and sensory properties of Cantonese sausages. Meat Science, Barking, v. 86, n. 2, p. 276-282, 2010. http://dx.doi. org/10.1016/j.meatsci.2010.04.014. PMid:20510531.

TRINDADE, M. A.; FElíClO, P. E.; CASTILLO, C. J. C. Mechanically separated meat of broilers breeder and white layer spent hens. Scientia Agricola, Piracicaba, v. 61, n. 2, p. 234-239, 2004. http://dx.doi.org/10.1590/S0103-90162004000200018.

UNIVERSIDADE ESTADUAL DE CAMPINAS - UNICAMP. Tabela Brasileira de Composição de Alimentos - TACO. 4. ed. rev. e ampl. Campinas: UNICAMP; NEPA, 2011.

XIA, S. H.; WANG, Z.; XU, S. Y. Characteristics of Bellamya purificata snail foot protein and enzymatic hydrolysates. Food Chemistry, London, v. 101, n. 3, p. 1188-1196, 2007. 